\title{
Integrative Approaches to Clinical Practice
}

\author{
F. Diane Barth
}

Published online: 26 April 2011

(C) Springer Science+Business Media, LLC 2011

\section{Introduction}

This special issue of the Clinical Social Work Journal is devoted to a contemporary problem that affects not only social workers, but in reality the entire field of psychotherapy. Appropriately, it grew out of a discussion on that completely modern tool, the internet listserv. A group of social work psychotherapists were discussing the question of whether or not it was acceptable, useful or even necessary to integrate different theories into the clinical work they were doing. As the discussion grew, the questions expanded and narrowed simultaneously. For example, we wondered if one does integrate, how does one do it? Which theories can be integrated, and which have to stand alone? Is it possible to be faithful to social work values and also to work psychodynamically with individuals? Can one utilize cognitive behavioral techniques and consider issues of transference and countertransference with the same clients? Does this apply to dialectical behavioral therapy (DBT)?

Every question led to another. Is it even possible to practice any kind of helping work in contemporary times without integrating in some way or another-sometimes without knowing that we have done it-ideas from a variety of other fields? What about mixing theoretical concepts from different psychodynamic perspectives? Some of Freud's ideas have long been assimilated into the language and thinking of the public at large; and often they are liberally mixed into attachment, relational, and even ego psychology—yet does mixing theories lead to muddled work?

F. D. Barth ( $\square)$

New York, NY, USA

e-mail: fdbarth@aol.com
Each of the authors included in this special issue have struggled with these and other questions about integrating theories, and they kindly share their thoughts and conclusions with us. Some have chosen to integrate apparently un-integratable theories and techniques, while others are less comfortable with such mixing of different approaches. Some are looking for ways to assimilate different psychodynamic theories, while others are searching for ways to utilize non-dynamic theories and techniques. The question always is: can ideas and theories be integrated without losing their individual value?

Wachtel (1997) writes that "psychodynamic and behavioral approaches to psychotherapy, and to the understanding of personality, are far more compatible than is generally recognized, and that an integration of the concepts and observations accumulated by these two approaches can greatly enrich our clinical work and our understanding of human behavior." (Wachtel 1997, p. 5).

There is yet another question that these authors consider. Do we even need theory? What is its point? Why bother? And if we bother, why not pick and choose what makes the most sense to us from several theories that we like and that make sense to us?

John M. Gedo and Fred Pine are two clinicians who developed different approaches to integrating theories of the mind based on psychoanalytic concepts. Pine's (1990) model allows for different theories to be integrated intact, as different "moments" of experience. Gedo's (1981) theory is that different concepts "could be conceptualized in one inclusive and consistent theory. (I)n adult life all of these diverse modes of functioning continue to be available to every individual. In every analysis, we must forever expect to encounter them all."(Gedo 1981, p. 312). Whether we integrate or do not integrate, whether we're doing psychoanalysis or DBT, EMDR or movement therapy, 
psychodynamic psychotherapy or family therapy, working with mostly healthy or very disturbed populations, the wealthy or the poor, the physically disabled or the psychologically damaged, we need theory to help ourselves think about what we are doing and why. The more we are able to think about what is happening-with them, with us, with clients' families, in the worlds they inhabit-the better able we will be to offer them a treatment designed for their needs.

Each of the nine articles in this journal addresses some of these questions about integrating theories, and thereby offers ways for clinicians to think about the work. Coming from different theoretical models, using different techniques and interventions, approaching the work from different perspectives, these authors offer distinct viewpoints on the question of integration of theories.

The issue begins with an article by Mary E. Conners, who credits relational theory with what she calls the "climate warming" that has allowed the once inviolable psychoanalytic theory to receive information and thinking from outside - and by the same token, has allowed nonanalytic theories to take in some of the ideas once only used in psychoanalysis. Thus, she suggests, therapists are now able to "assimilate symptom focused techniques into dynamic psychotherapy.” Drawing from self psychology and attachment theory for ideas about development and treatment, Conners utilizes interventions from behavioral and cognitive behavioral traditions and mindfulness based strategies to help clients learn new ways to cope with troubling symptoms.

The next articles are written from the perspective of psychodynamic psychotherapy. Each author explores the integration of different theories and/or different approaches to the work.

In the second article, Paul Gedo questions the very essence of theory-is it even necessary to therapeutic practice? In an institution for troubled adolescents who often acted out in seriously self-destructive ways, staff sometimes experienced "intense and raw emotions." Splitting was common. The overall approach involved an effort to provide new and health-promoting attachments to these youngsters who had often had severe losses in their lives. Yet managing counter-transference reactions was also part of the work. Using an extensive clinical example, Gedo explains how theory was integrated into the process for clients and therapists; and concludes that understanding and thinking about what is happening between client and therapist, as well as among the therapeutic staff, is a crucial part of the therapeutic experience.

Morris Eagle discusses the interplay between interpretation and the therapeutic relationship. Noting that different psychoanalytic theories have been integrated-sometimes intentionally, sometimes accidentally—from Freud's time on, Eagle brings together Weiss and Sampson's (1986) theory of "test-passing," Fairbairn's (1958) focus on the therapist as a good object, and Mitchell's (1988) thinking about the importance of a new object-relationship with the therapist. Eagle suggests that any interpretation needs to be understood not only in terms of its content, but also within the context of the therapeutic relationship in which it takes place.

In her article on the question of self-disclosure, Cathy Siebold explores the issue of self-disclosure on the part of a therapist. It is, she says, a controversial and complicated theoretical question, with strong opinions on both sides of whether it is useful or harmful to the therapeutic work. Bringing the therapist's needs and desires into the mix, she asks if there are times when a decision not to reveal something is better for a client because it is better for the therapist? Relational, intersubjective and symbolic interactionist theories are integrated in her exploration of this question. A clinical example illustrates the complexities of this question.

Francine Lapides utilizes a psychodynamic approach to couples therapy in article 6; but as anyone who has worked in this medium knows, there are often times when a couples' therapist must use non-exploratory tools in order to help her or his clients change troubling behaviors and patterns. Lapides writes that adult romantic relationships depend on what psychoanalysts call "implicit" or "right brain, attachment-related, nonverbal exchanges" that often occur out of conscious awareness. Combining a mix of neuroscience, attachment theory and psychodynamic theory, Lapides offers a fascinating clinical example and a detailed explanation of the ways that she integrates these ideas in her work with a troubled couple.

Each of the next contributors present a specific nonpsychoanalytic psychotherapy-Dialectical Behavior Therapy (DBT), Eye movement desensitization and reprocessing (EMDR) and movement therapy-and explore on one hand how much psychodynamic thinking is included in the work and on the other, whether or not the techniques they present can be integrated into a psychodynamic approach.

Alexander Chapman, Brianna Turner, and Katherine Dixon-Gordon write, "when asked to identify their theoretical orientation, most therapists identify themselves as 'eclectic' or 'integrative'". They suggest that since its creation by Linehan (1993), DBT has increasingly been integrated into a variety of clinical and theoretical frameworks. This approach is, they suggest, a basically integrative approach. In their discussion, they consider both how other theoretical frameworks have been integrated into DBT and how DBT has been integrated into a variety of other clinical approaches. They also examine some of the issues that can emerge when therapists who utilize and 
have been trained in other approaches bring DBT techniques into their work. Their ideas about how to deal with these issues are sure to be useful to anyone who has tried to integrate DBT into another framework.

In the next article, Frances LaBarre, a movement therapist, writes that action was once believed to be the antithesis of thought and therefore purposefully excluded from psychodynamic work. Today, she says, we recognize that the physical and psychological are closely linked. In her paper she explores traditional psychoanalytic terms like transference and countertransference from a movement or "kinetic" perspective. Suggesting that "we think with our bodies in action," she presents clinical examples that illustrate ways that a client's body can express both thoughts and feelings.

In the final article in this section, Francine Shapiro and Deany Laliotis present EMDR as "a comprehensive psychotherapy approach that is compatible with all contemporary theoretical orientations." Offering their research on the efficacy of the work, they suggest that EMDR can be utilized in trauma treatment as well as a broad range of clinical issues. Like a number of other authors in this special issue, they draw on neuroscience for explanations of the efficacy of this technique. However, unlike most of the other authors in this issue, they emphasize that EMDR is "a distinct form of psychotherapy," which utilizes psychodynamic concepts, but not one that should necessarily be integrated into other frameworks.

The final two articles take us back to the question of integrating theories in clinical social work.

Ghislaine Boulanger offers a short personal essay in which she attempts to think out her own theory of integration. A psychoanalyst who has written about and worked with adult trauma victims, she differentiates between eclectic and integrative approaches, and comes to the conclusion that integration requires a thoughtfulness and understanding of different modalities and theories of the mind. The integrator looks for overlapping ideas, but always in the service of moving the clinical work forward. "An integrative approach amounts to informed flexibility," she tells us; and she concludes that integration may be more the norm than even the most orthodox practitioners realize.

The issue ends with Alex Gitterman and Nina Heller making a plea for social work practitioners "to identify with and adopt distinctive social work perspectives and practice models or approaches rather than solely embrace models or approaches developed by and for other professions." They review the ecological and eco-systems models of social work practice and integrate them with four major social work approaches. They discuss the ways that these models can be utilized to integrate both psychodynamic understanding and interventions with concrete and behavioral interventions aimed at symptom reduction.

I thank each of these authors for taking the time to provide these excellent and thought-provoking contributions to the ongoing discussion about integration of theories and models of intervention in clinical work. I think any clinician, no matter what his or her personal and theoretical orientation, will find these thoughts extremely helpful in their practice.

\section{References}

Fairbairn, W. R. D. (1958). On the nature and aims of psychoanalytical treatment. International Journal of Psychoanalysis, 39, 374-385.

Gedo, J. E. (1981). Measure for measure: A response. Psychoanalytic Inquiry, 1, 289-316.

Linehan, M. M. (1993). Cognitive-behavioral treatment of borderline personality disorder. New York: Guilford Press.

Mitchell, S. (1988). Relational concepts in psychoanalysis: An integration. Cambridge, MA: Harvard University Press.

Pine, F. (1990). Drive, ego, object, and self: A synthesis for clinical work. New York: Basic Books.

Wachtel, P. (1997). Psychoanalysis, behavior therapy, and the relational world. Washington, DC: American Psychological Association.

Weiss, J., Sampson, H., \& The Mount Zion Psychotherapy Research Group. (1986). The psychoanalytic process: Theory, clinical observation, and empirical research. New York: Guilford Press.

\section{Author Biography}

F. Diane Barth LCSW, is a clinical social work psychotherapist in private practice in New York City. She works with adults and adolescents and runs study groups and workshops for therapists. She has consulted with the Children's Aid Society, Williams College, and others on issues related to separation and attachment. Her articles appear in the Clinical Social Work journal, Psychoanalytic Psychology, other journals and in numerous books. She wrote Daydreaming: Unlock the Creative Power of Your Mind, has taught several online courses and has a blog called "Off the Couch" at http://www. psychologytoday.com/blog/bloggers/f-diane-barth-lcsw. 